\title{
PREVALENCE OF DOMESTIC VIOLENCE DURING PREGNANCY IN OLEH, A SUBURBAN ISOKO COMMUNITY, DELTA STATE, NIGERIA
}

\author{
*V.O. Awusi, ${ }^{*}$ V. O. Okeleke, B. E. "Ayanwu \\ "Department of Family Medicine, Faculty of Medical Sciences, Delta State University, \\ Abraka, Delta State, Nigeria. \\ ${ }^{* *}$ Central Hospital, Oleh, Isoko South Local Government Area, Delta State, Nigeria.
}

\section{Correspondence:}

Dr. V.O. Awusi,

Department of Family Medicine, Faculty of Medical Sciences,

Delta State University, Abraka,

Delta State, Nigeria.

Email: alpha.medicalcentre@yahoo.com

\section{ABSTRACT}

Domestic violence against pregnant women exposes victims to higher risk of pregnancy complications.

The aim of this questionnaire-based, cross-sectional study was to determine the prevalence, knowledge and perception of domestic violence amongst 400 consecutive pregnant women attending the ante-natal clinic of Central Hospital, Oleh. The mean age of the respondents was $28 \pm 4.3$ years (Range 15 - 44years) and, $82 \%$ of them attained at least secondary school education. Three hundred and sixty eight (92\%) showed complete knowledge of domestic violence. A total of $144(36 \%)$ of the women had experienced domestic violence during pregnancy. Domestic violence experienced were in the forms of verbal (58\%), physical (31\%) and sexual $(11 \%)$ abuses. The husband was the commonest offender (92\%). Some of the women felt domestic violence in pregnancy was always (12\%) or under certain conditions (25\%) excusable; and $77 \%$ of them would keep domestic violence in pregnancy secret. It is recommended that public awareness, about the inherent dangers associated with this act should be improved.

Key words: Domestic violence, pregnant women; suburban community.

\section{INTRODUCTION}

Domestic violence (DV) against women refers to any type of harmful behaviour directed at women and girls by significant others such as the husband/spouse ${ }^{1,2}$. It can take various forms and could be physical, verbal or sexual ${ }^{3,4}$. It can also be in form of threats of such acts, coercion or arbitrary deprivation of liberty, whether occurring in public or private life ${ }^{4}$. DV against women cuts across ages, ethnicity, religion and educational barriers ${ }^{1}$; and its prevalence ranged between 17-37\%, with considerable regional variation ${ }^{4,5}$. Low socio-economic and educational status, early marriage, alcohol and substance abuse by the partner and unemployment have been suggested as its risk factors ${ }^{3,6}$. Most countries and religions frown at DV against women, but because the cultures of the people of these countries condone it, the problem has persisted ${ }^{4}$. This explains the "acceptable" attitude of women and men to DV, and why some persons even justify it ${ }^{4,5}$.

The Nigeria National Reproductive Health Policy ${ }^{7}$ lists gender-based violence as one of the key issues of reproductive health concern and has as one of its aims the limiting of all forms of gender-based violence. When it involves pregnant women, it calls for a closer and urgent attention because of the greater danger it entails. DV against pregnant 
women has been reported in Nigeria ${ }^{8,11}$ and worldwide ${ }^{4,9}$. Studies . $^{9,22}$ have shown that DV against pregnant women is more prevalent than pregnancy-related complications such as pre-eclampsia and gestational diabetes, that have detrimental effects on the physical, social, reproductive and psychological well-being of the mother as well as presenting risk for the unborn baby. The impact of DV on pregnant women is increasingly being recognized as an important public health issue. It is in this light this, the present study attempts to document the prevalence, knowledge and perception of DV amongst pregnant women in Oleh, a suburban community in Isoko South local government area of Delta State, Nigeria, with the aim of using such information to highlight the increasing presence of DV against pregnant women in our society and proffer solutions to the problem.

\section{MATERIALS AND METHODS}

Consecutive patient recruitment method was used in selecting the subjects. A minimum sample size of 310 was calculated using the formula ${ }^{23}: \mathrm{N}=\mathrm{Z}^{2}(P)$ $(1-P) / d^{2}$ where, $N=$ minimum sample size at $95 \%$ confidence level; $Z=1.96$; $d$ $=$ precision: the difference between the true population rate and your sample rate that you can tolerate; $\mathrm{P}=$ population prevalence. A study has shown that the prevalence of DV against pregnant women was $28 \%{ }^{14}$; therefore $\mathrm{N}=(1.96)^{2}$ $(0.28)(0.72) /(0.05)^{2}=310$.

Four hundred consecutive pregnant women attending the ante-natal clinic of Central Hospital, Oleh, from February 1st 2008 - January 31st 2009 were served with pre-tested structured questionnaire by two of the authors (A.V.O. and O.V.) after obtaining their informed consent. The questionnaire included questions on the socio-demographical status of the women; and also about their knowledge, perception and the types of DV, how long ago the DV occurred. DV that occurred more than 3years before the study were excluded to minimize recall bias $^{23}$ and also 3years falls roughly on a probable last pregnancy taking the reported ${ }^{20}$ median birth interval of 31 months among Nigerian women into consideration.

Physical abuse was defined as beating/flogging/slapping etc. Verbal abuse was defined as exposure to partner's insults and sexual abuse as experience of any form of forced sex.

The data was analyzed using Epi-info Version 6 Statistical software. The level of significance was set at $5 \%(P<0.05)$

\section{RESULTS}

The mean age of the respondents was 28 \pm 4.3 years (Range $=15-43$ years); and majority were in age group $26-30$ years $(48 \%)$, educated up to secondary school level $(82 \%)$, married $(92.8 \%)$, of Isoko extraction $(91 \%)$ and had knowledge of DV $(92 \%)$.

Table I shows the Age - DV status distribution of the women. One hundred and forty-four (36\%) of them had experienced DV during pregnancy, while $256(64 \%)$ did not. DV was highest in the $21-25$ years $(41 \%)$ and $26-30$ years $(40 \%)$ age groups.

Table II shows the forms of DV experienced by the 144 respondents; 83 (58\%) was verbal, 45 (31\%) physical and $16(11 \%)$ were forced to have sex.

The commonest offender was the husband (92\%) (Table III).

On the women' view about DV against pregnant women (Table IV), some felt it was always $(12 \%)$ or under certain conditions (25\%) excusable; however, majority $(60 \%)$ felt it was not excusable.

On what their reaction will be if they experience DV against them (Table V), $77 \%$ would keep it secret; $8 \%$ would report to family, $4 \%$ to In-laws, $2 \%$ each to close friend and doctor, and $3 \%$ to clergy. Only $3 \%$ will report to the authority while $2 \%$ were undecided. 
Table I: AGE - DV STATUS DISTRIBUTION OF THE RESPONDENTS ( $\mathrm{N}=400)$

\begin{tabular}{lccr}
\hline Age $($ Years $)$ & Experienced DV $(\%)$ & Did not experience DV $(\%)$ & Total \\
\hline$<16$ & $3(21)$ & $11(79)$ & 14 \\
$16-20$ & $4(14)$ & $24(86)$ & 28 \\
$21-25$ & $32(41)$ & $47(59)$ & 79 \\
$26-30$ & $78(40)$ & $115(60)$ & 193 \\
$31-35$ & $19(39)$ & $30(61)$ & 49 \\
$36-40$ & $6(22)$ & $21(78)$ & 27 \\
$>40$ & $2(20)$ & $8(80)$ & 10 \\
Total & $144(36)$ & $256(64)$ & 400 \\
\hline
\end{tabular}

Table II: TYPE OF DV EXPERIENCED BY RESPONDENTS ( $\mathrm{N}=144)$

Type

Physical

45

31

Verbal

83

16

144

No.

$\%$

Sexual

Total

100

Table III: THE CULPRIT RESPONSIBLE FOR DV ( $\mathrm{N}=144$ )

\begin{tabular}{lcc} 
CULPRIT & FREQUENCY & $\%$ \\
Husband & 132 & 92 \\
Boyfriend & 7 & 5 \\
In-laws & 3 & 2 \\
Others & 2 & 1 \\
Total & 144 & 100 \\
\hline
\end{tabular}

Table IV: VIEW ABOUT DV AMONGST THE RESPONDENTS ( $\mathrm{N}=400)$

VIEW

Always Excusable

Excusable sometimes

Not Excusable

Undecided

Total

\section{FREQUENCY}

46

98

240

16

400
11.5

24.5

60

4

$\%$

100 
Table V: REACTION OF THE RESPONDENTS TO DV $(\mathbf{N}=400)$

\section{REACTION TO DV}

Report to Authority

Keep it secret

Report to family

Report to in-laws

Tell a close friend

Report to doctor

Report to clergy

Undecided

Total

\section{FREQUENCY}

10

308

30

17

8

6

12

9

400
$\%$

3

77

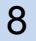

4
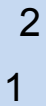

3

2

100

\section{DISCUSSION}

Most of the pregnant women (victims) were aged 21 - 30years (76\%) which is comparable to findings from Enugu ${ }^{17}$, Zaria $^{14}$ and Ghana ${ }^{5}$. This is the most fertile age period for women and so they are more likely to be victims of DV in pregnancy. Most of our respondents were Isoko-speaking, which is the predominant tribe in this part of Delta State, Nigeria.

The family unit which is seen as a medium of socialization has been reported $^{12}$ to be a place where much violence is directed at its female members. It was, therefore, not surprising that $92 \%$ of our respondents have either witnessed or heard about DV against pregnant women. This is similar to findings from Abuja $-92.9 \%{ }^{13}$ and Zaria $-56 \%{ }^{14}$ which reported that majority of their respondents had knowledge of DV in pregnancy. Thirty-six percent $(36 \%)$ of pregnant women, in this study, had experienced DV either in index pregnancy or in a previous pregnancy. It was higher than findings from other studies $-14 \%^{3}, 25.7 \%{ }^{6}$ and $28 \%{ }^{14}$, but comparable to a study from Abuja$37.4 \%{ }^{13}$. It was however; lower than others $-52.6 \%{ }^{15}, 52 \%{ }^{16}$ and $47.1 \%{ }^{11}$.

As in other studies - $66.4 \%{ }^{13}$, $52.3 \%{ }^{11}$ and $49.8 \%{ }^{6}$, majority (58\%) of our victims of DV were verbally abused.
This was followed by physical abuse (31\%), which is comparable to other studies $-29.6 \%^{6}$ and $28.9 \%{ }^{11}$; higher than others - $25 \%{ }^{11,} 23.4 \%{ }^{13}$ and $10.7 \%{ }^{18}$ but lower than that from Zaria $36 \%{ }^{14}$. Sexual abuse was the least form of DV experienced by pregnant women in this study $(11 \%)$. This was the same in other studies $-5.6 \%{ }^{3}, 9.1 \%^{19}, 10.2 \%^{13}$, $10.8 \%^{6}, 14.2 \%^{11}$ and $22 \%{ }^{14}$. Although majority $(60 \%)$ of our respondents felt DV against pregnant women was not excusable, as in other studies $-81.9 \%{ }^{13}$ and $48.9 \%{ }^{14}$, some of them $(25 \%)$ felt it was excusable under certain conditions as also reported in other studies $49 \%{ }^{20}, 21.9 \%{ }^{14}$ and $18 \%{ }^{13}$. This attitude of these women is capable of truncating efforts geared towards eliminating this act; as women are known to be closer and emotionally attached to culturalassociated events, such as pregnancy, in our communities ${ }^{21}$. This become more worrisome when it is realized that some of the women (12\%) felt DV in pregnancy was always excusable as also reported in a study from Zaria- $14.6 \%{ }^{14}$. Although the women who experienced DV, in this study, did not report any DVassociated injury (not in our result), it has been reported $^{3,19}$. Obstetric complications that may follow DV in pregnancy include 
inevitable abortion, abruptio-placenta and intra-uterine death ${ }^{22}$.

It is important to note that, although, the constitution of the Federal Republic of Nigeria allows respect of human right ${ }^{12}$, section 55 of the penal code permits a husband to physically abuse to correct his wife as long as they are married according to the native/custom law in which such correction is recognized as lawful; although pregnant wife/women was not mentioned among the groups (servants/child/pupil/wife) to be so disciplined in the penal code. This may be one of the reasons why majority of the victims $(77 \%)$, in this study, would rather keep DV against them secret; as also reported in other studies - 99\% ${ }^{11}$ and $36 \%{ }^{14}$ and $29.7 \%^{3}$ which reported that majority of the respondents would keep DV against them secret. One of the reasons given for this attitude was the fact that the commonest offender of the act was the husband ${ }^{13}$, whom she still loves; others are fear of ridicule from family members and friends, dependence economically on her husband, reprisal from husband if apprehended by law enforcement agents and also the probability that the authorities may advise out of court settlement to avoid dabbling into family matters ${ }^{4}$. In this study, the husband was the commonest offender, responsible for $92 \%$ of the cases; as in other studies $-78.7 \%{ }^{11}, 74.2 \%{ }^{13}$ and $56 \%{ }^{14}$.

\section{CONCLUSION}

This study showed that DV against pregnant women is common in Oleh, a suburban community of Delta State, Increasing public awareness, through enlightenment and education campaigns, emphasizing the inherent dangers associated with the act will go a long way in discouraging the perpetrators. The suggested $^{14}$ screening for DV in routine ante-natal clinic should only be to the extent of treating the woman or counselling/health educating both parties. Also women should not encourage DV against women as sometimes done by mothers or sister-in-laws. Shelter houses should be established to provide comfort for the pregnant woman who is a victim of DV. Making DV against pregnant women a punishable offence so as to discourage perpetrators (mostly intimate partners), should be taken with caution as it may be counterproductive. And finally, there is need for further study in order to identify and ultimately eliminate the risk factors.

\section{ACKNOWLEDGEMENT}

We wish to thank all Nursing Staff and Medical Assistants of ante-natal clinic of the Central Hospital, Oleh, for their immense contribution to this study.

\section{REFERENCES}

1. Little KJ. Screening for domestic violence, identifying, assisting and empowering adult victims of abuse. Postgrad. Med. 2000; 108(1): 4-9.

2. Verku A, Addisie M. Sexual violence among female high school students in Deberk, North-West Ethiopia. East Afr. Med. J. 2002; 79: 96-9.

3. Fisher $M$, Yassour-Borochowitz D, Neter E. Domestic abuse in pregnancy: results from a phone survey in northern Israel. Isr.Med.Assoc.J.2003; 5:35-9.

4. Ending violence against women. In: Population reports. Volume XXVII, No.4, December 1999.

5. Kwawukume EY, Kwawukume SB. Violence against pregnant women the patients' perspective. Nig. J. Clin. Pract. 2001; 4:76- 9.

6. Erhan D, Yasemin A, Canan G, Mehmet T, Ahmet A. Prevalence of domestic violence during pregnancy in a Turkish communuty. Southeast Asian J. Trop. Med. Pub. Hlth.2007; 38(4): 754-60. 
7. $\mathrm{FMOH}$. Nigeria National Reproductive Health Policy and Strategy, 2001.

8. Ilika AL, Okonkwo IP, Adeogu P. Intimate partner violence among women of child-bearing age in a primary health care centre in Nigeria. Afr. J. Reprod. HIth. 2002; 6 (3):53-8.

9. Leuvng WC, Leung TW, Lam YY, Ho PC. The prevalence of domestic violence against pregnant women in a Chinese community. Int. J. Gynaecol. Obstets. 1999; 1:23-30.

10. Heise L, Elisberg M, Gotthermoeller M. Ending violence against women. Population Reports 1999; Series 1 (11).

11. Ezechi OC, Kalu BK, Ezechi LO, Nwokoro CA, Ndububa VI. Prevalence and pattern of domestic violence against pregnant Nigerian women. J. Obstets. Gynaecol. 2004; 24(6): 65256.

12. Suleiman K. In: Domestic violence against women under international law. In: Long essays for LL.B. degree. Ahmadu-Bello University, Zaria, Nigeria 2001; pp. 28-33.

13. Efetie ER, Salami HA. Domestic violence on pregnant women in Abuja, Nigeria. J. Obstets. Gynaecol.2007; 27(4): 379-82.

14. Ameh N, Abdul MA. Prevalence of domestic violence amongst pregnant women in Zaria, Nigeria. Annals of African Medicine 2004; 3(1): 4-6.

15. Okemgbo CN, Omideyi AK, Odimegwu CO. Prevalence, patterns and correlates of domestic violence in selected Igbo communities of Imo State, Nigeria. Afr. J. Reprod. HIth. 2002; 6:101-14.
16. Coker AL, Smith PH, McKeown RE, King MJ. Frequency and correlates of intimate partner violence by type: Physical, sexual and psychological battering. Am. J. Public HIth. 2000; 90: $553-9$

17. Ikeme, ACC, Ezegwu H, Onwasoigwe CW. Domestic violence against pregnant Nigerian women. In: Abstracts of the 35th annual general meeting and scientific conference of SOGON.

Trop.J.Obstets.Gynaecol.2001; 18(suppl. 1): 42.

18. Lown EA, Vega WA. Prevalence and predictors of physical partner abuse among Mexican-American women. Am. J. Public Hlth.2001; 91: 441-5.

19. Turkish Republic Prime Ministry Directorate General on the status and problems of women. The reasons and consequences of domestic violence. Bizim Buro Basimevi 2000; 86: 13541.

20. National Population Commission (NPC) Nigeria and ORC Macro.2004. Nigeria Demographic and Health Survey 2003. Calverton, Maryland: National Population Commission and ORC Macro.

21. Chidambaram VC. Cleland JG, Goldman N, Rutstein S. An assessment of the quality of WFS demographic data source In: The analysis of maternity histories, edited by Allan G. Hill and Williams Brass Liege, Belgium, Editions DerouauxOrdina, 1992: 183-215.

22. Program for Appropriate Technology in Health (PATH). Violence Against women: Effects on Reproductive Health. OUTLOOK 2002; 20(1): 1-8.

23. Oyejide CO. Health Research Methods for Developing Country Scientists. Codat Publications, Ibadan, Nigeria 1992; pp. 59-63. 